\title{
RESEÑAS
}

\section{SELECTED PAPERS ON GREEK THOUGHT. ALFONSO GÓMEZ LOBO (EDS. MARCELO D. BOERI Y ALEJANDRO G. VIGO). SANKT AUGUSTIN: ACADEMIA VERLAG, 2017. 348P}

Este libro constituye una recolección de un total de 26 trabajos del filósofo chileno Alfonso Gómez-Lobo, tristemente fallecido en 2011, que versan sobre diferentes tópicos dentro de la filosofía y el pensamiento griego. Estos trabajos, en una edición a cargo de dos especialistas en filosofía antigua y amigos del difunto filósofo, exhiben de modo representativo los aportes de Gómez-Lobo al estudio especializado de la filosofía, así como su propio talante filosófico.

El volumen tardó, por una larga serie de dificultades, varios años en poder ser entregado al público. Gracias a un gran esfuerzo de recopilación y edición de Alejandro Vigo y Marcelo Boeri, con la ayuda de Sylvia Eyzaguirre y el Centro de Estudios Públicos, este libro pudo, finalmente, ver la luz y ser presentando por los editores en el mismo CEP en mayo de 2018. Así, han quedado a disposición para futuros lectores, en un solo volumen, algunas de las grandes contribuciones de Alfonso Gómez-Lobo. Con este aporte editorial, su obra puede ser más fácilmente consultada y está a disposición de los interesados en la filosofía antigua de manera mucho más provechosa.

Los trabajos recopilados en este volumen ponen de manifiesto la profundidad, rigor y claridad expositiva que caracterizaban el trabajo de Gómez-Lobo. Estas virtudes, junto a su penetración filosófica, le permitieron posicionarse en el primer nivel de la discusión filosófica y la investigación especializada a nivel mundial. Gómez-Lobo no solo entró en discusión con algunos de los grandes intérpretes y estudiosos de la filosofía antigua, sino también pudo ejercer una influencia positiva con sus originales interpretaciones y, en reiteradas ocasiones, provocativas tesis. Quizá el caso más señalado sea su interpretación de la dialéctica en el Sofista de Platón, la cual introdujo una alternativa a la clásica interpretación de Stenzel.

Como ya indicábamos, este volumen, presentado en 2018, contiene 26 trabajos publicados en diferentes revistas y libros a lo largo del período 
comprendido entre 1977 y 2006. Esto podría sugerir que los trabajos apuntan en diferentes direcciones y su compilación en un mismo volumen posee, más bien, una unidad de carácter accidental. Sin embargo, sin mucha dificultad, es posible rastrear una coherencia temática entre varios de los trabajos, así como aspectos metodológicos y de contenido que atraviesan toda la obra.

Por de pronto, esto se puede afirmar de los trabajos acerca del Poema de Parménides que principian el volumen (capítulos 1 y 2) y los detallados análisis sobre algunos pasajes del Sofista de Platón (capítulos 9, 10 y 11). En estos, se evidencia una preocupación por temáticas ontológicas, pero bajo la consideración crítica del rigor analítico y con el aprovechamiento de resultados de los estudios en filosofía del lenguaje, semántica, lógica y filología. En este contexto destaca la influencia de trabajos como el de Charles Kahn sobre la semántica de la copula 'ser' en el griego antiguo, el interés que el autor tiene por Frege o el constante recurso a aparatos simbólico-formales para la elucidación de sus argumentos y tesis. En efecto, la comprensión de la prioridad del uso del verbo 'ser' en su valor predicativo y no existencial, lleva, entre otras cosas, a Gómez-Lobo a su especial reconstrucción de la ontología de estos filósofos.

En esta línea de análisis, y con estas mismas influencias, Gómez-Lobo desarrolló una lectura predicamentalista de Aristóteles que rindió frutos especialmente para interpretar la Metafísica (capítulos 21, 22 y 23) y los Analíticos Posteriores (capítulos 13, 14 y 15), dos obras a las que dedicó algunos de sus más significativos estudios. El argumento, por ejemplo, que desarrolla para una lectura predicamentalista de la metafísica aristotélica depende de la interpretación de la estructura semántica del verbo "ser" que toma de los trabajos de autores como Kahn. La apuesta de Gómez-Lobo se encuentra en la negación del uso existencial del verbo "ser", viendo allí, por el contrario, un uso predicamental con elipsis del predicado y del sujeto. Esto le permite llegar a conclusiones como que la filosofía primera de Aristóteles no es otra cosa que "una ciencia concebida básicamente como una indagación del principio y la causa por la cual los atributos esenciales pertenecen a sus sujetos" (p. 280). A juicio de Gómez-Lobo, al no tematizar el verbo 'ser' en su uso existencial, la metafísica aristotélica ha de entenderse en esta lógica predicamental.

Pero, a su vez, estos resultados en sus interpretaciones de filosofía teórica, le permitieron a Gómez-Lobo desplazarse hacia problemas de la filosofía práctica. Destaca, aquí, su reconstrucción del célebre argumento del ergon planteado por Aristóteles en el primer libro de la Ética Nicomaquea, el 
cual Gómez-Lobo intenta entender bajo la restricción de privar de recursos metafísicos a la argumentación del Estagirita (capítulos 16 y 17).

Sus trabajos, empero, se enmarcan en un contexto general de discusión. Estas tesis que, a veces, pueden resultar provocativas y polémicas, tienen en vista una discusión general de la apropiación de la filosofía antigua. Gómez-Lobo, ciertamente, forma parte de una reacción en las interpretaciones de la filosofía griega, especialmente Aristóteles, que se propone hacer frente a la influencia ejercida por la filosofía heideggeriana, cuestión que Alejandro Vigo destacó en la presentación de esta publicación. Así, manteniendo la preocupación por temáticas centrales de la ontología, se toman en cuentas todos los elementos de la crítica especializada que hemos indicado a fin de dotar de un nuevo rigor al análisis de estos problemas.

Por último, querríamos destacar otra unidad temática dentro del volumen. Estos son los diferentes trabajos sobre ética y racionalidad práctica. Además, de los ya mencionado sobre la fundamentación de la ética aristotélica, en este volumen se encuentran otros destinados al estudio de la racionalidad práctica en Aristóteles e incluso una aplicación de la filosofía del Estagirita a un problema contemporáneo de bioética (capítulo 26). También, en este volumen, encontramos dos trabajos de Gómez-Lobo en los que presenta su reconstrucción de la ética del Sócrates platónico (capítulos 5 y 6). Su propuesta, no exenta de dificultades, propone una fundación axiomática de la ética socrática, la cual, por medio de inferencias deductivas, orientaría los dichos y argumentos de Sócrates, así como sus propias acciones.

Estas líneas temáticas que hemos esbozado no agotan, por de pronto, los intereses de Gómez-Lobo que se ven reflejados en este volumen. Hay también un trabajo sobre Heródoto (capítulo 3), uno sobre Tucídides (capítulo 4), estudios específicos sobre temas del Eutidemo o el Eutifrón (capítulos 7 y 8), entre otras cosas. Los intereses del filósofo chileno eran variados y sus aportes múltiples. Su obra en general y los trabajos aquí recopilados en particular son también una invitación a la vuelta a los clásicos con el riguroso examen y estudio que merecen.

A fin de cuentas, este proyecto de edición de los trabajos de GómezLobo se nos presenta como una oportunidad de volver su obra y encontrarnos con importantes y originales trabajos de exégesis de la filosofía griega que abordan algunas de las cuestiones más fundamentales del pensamiento filosófico. Aquí tenemos en frente un completo y representativo compendio de la obra de Gómez-Lobo que, ahora editada en un volumen, se encuentra mucho más fácilmente accesible para todos los 
interesados en la filosofía griega y en el pensamiento de este gran filósofo chileno. No nos queda ninguna duda de que sus trabajos seguirán siendo de gran interés para todos quienes se encuentran en el mundo del estudio y desarrollo de la historia de la filosofía.

\section{Raimundo Cox D.}

Universidad de los Andes

rrcox@miuandes.cl 